\title{
Public Attitudes on Funding Oil Pollution Cleanup in the Chinese Bohai Sea
}

\author{
Xin Liu ${ }^{\dagger *}$, Guangchen Pan ${ }^{\ddagger}$, Yebao Wang ${ }^{\ddagger \#}$ Xiang Yu ${ }^{\ddagger \#}$ Xiaoke $\mathrm{Hu}^{\dagger}$, Hua Zhang ${ }^{\dagger}$, and Cheng Tang \\ Key Laboratory of Coastal Environmental Processes and Ecological Remediation \\ Chinese Academy of Sciences ( CAS) \\ Shandong Provincial Key Laboratory of Coastal Environmental Processes
}

Yantai Institute of Coastal Zone Research, CAS

Yantai, Shandong 264003, P. R. China

Yantai University

Yantai, Shandong 264005, P. R. China

"University of Chinese Academy of Sciences

Beijing, 100049, P. R. China

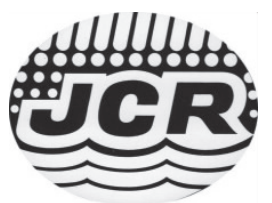

www. JCRonline. org

\begin{abstract}
Liu, X.; Pan, G. C.; Wang, Y. B.; Yu, X.; Hu, X. K.; Zhang, H., and Tang, C., 2016. Public attitudes on funding oil pollution cleanup in the Chinese Bohai Sea. In: Harff, J. and Zhang, H. (eds. ), Environmental Processes and the Natural and Anthropogenic Forcing in the Bohai Sea, Eastern Asia. Journal of Coastal Research, Special Issue, No. 74, pp. 207-213. Coconut Creek (Florida), ISSN 0749-0208.

The loss in value of coastal resources due to oil spills is difficult to determine as the degraded areas are typically neither bought nor sold and have no transaction history. We used a questionnaire by Liu et al. (2009) and Choice Experiments (CEs) methodology to place values on coastal resources including coastal water, beaches, and sea birds in the Chinese Bohai Sea. Survey results showed that during spill response actions, coastal water, and beaches were of equal concern to Chinese households while sea birds were of somewhat less concern. Respondents with higher education and fewer children and those with relatively greater household income were more likely to state they were willing to pay for oil spill cleanup costs. Age of respondent was negatively correlated to willingness to pay for cleanup. We also compared valuations of coastal resources with studies conducted in North America and Europe making it possible to test the consistency of coastal resource valuation across continents.
\end{abstract}

ADDITIONAL INDEX WORDS: Oil spill, contingency management, choice experiments, willingness to pay, coastal resources.

\section{INTRODUCTION}

Oil spills are frequent occurrences in the Chinese Bohai Sea due to the extensive maritime transportation and exploitation of offshore oil fields. A Portuguese oil tanker named "ARTEAGA" stranded 4. 3 nautical miles off Dalian Harbour on April 3, 2005. As a result, hundreds of tons of heavy oil spilled into the sea. On June 4, 2011, oil was observed on the sea water surface near platform B in an offshore oil drilling field named Penglai 19-3 operated by ConocoPhillips China Inc. ( COPC). This accident was a consequence of a geological fault during the drilling process ( COPC, 2012). According to COPC, approximately 723 barrels $\left(115 \mathrm{~m}^{3}\right)$ of oil and 2,620 barrels $\left(416 \mathrm{~m}^{3}\right)$ of mineral oil-based drilling mud seeped into the Bohai Sea. By June 17, the State of Ocean Administration ( SOA) reported that $840 \mathrm{~km}^{2}$ of formerly clean coastal water was severely polluted.

Spilled oil, containing toxic substances, pollutes the coastal environment and threatens economic uses of coastal resources. However, most coastal resources such as beaches, water, and bird life do not have a monetary value, making it difficult to assess the value of environmental damage caused by oil spills. In

DOI: 10.2112/SI74-018. 1 received ( 4 December 2014); accepted in revision (31 August 2015).

"Corresponding author: xliu@ yic. ac. cn

${ }^{\circ}$ Coastal Education and Research Foundation, Inc. 2016 contrast, local fishery production was significantly reduced after the Penglai 19-3. As a result, some local fishermen claimed a total income loss of CNY 1.0 billion ( CNY: Chinese Yuan) for damages ( Liu and Zhu, 2014).

The Prestige oil spill in 2002 produced major environmental damage and economic losses. The damages were estimated to be at least 4328 million by the public prosecutor. However, the Spanish State and the International Oil Pollution Compensation Funds (IOPC Funds) advanced only 151 million to compensate victims and mitigate the damages. The super tanker Exxon Valdez spilled 41.6 million liters of crude oil into Prince William Sound, Alaska which resulted in 4262 million USD damage (Alló et al., 2013; Birkland and Lawrence, 2002). The Exxon Valdez spill resulted in the enactment of the Oil Pollution Act of 1990 (OPA $90)$, which increased oil spill liability and damage compensation (Birkland and Lawrence, 2002). Comparisons of many oil spill cases show that there are great disparities between the requested and granted compensation. The ecological functions of coastal environments do not always have an obvious economic value ( Constanza et al., 1997) and are typically ignored in compensation negotiations. To improve this, the USA revised the Natural Resource Damage Assessment (NRDA) rules and procedures in 1996. The updated NRDA rules are based on a stated preference method (i. e., contingent valuation method), which is assessed by a survey determining a respondent's willingness to pay ( WTP) 
( Ofiara, 2002).

Extensive contingent valuation studies on oil spills have been conducted in developed regions such as North America and Europe. Very few such studies have been conducted in China. In the case of the Penglai 19-3 oil spill, the responsible oil company ( COPC) provided no direct compensation for the ecological damage of the coastal environment, in part due to limited information available about the monetary benefits of coastal habitats to society (Ojeda et al., 2008; Spurgeon, 1999; Stål et al., 2008). Additionally, evaluating cleanup strategies and preparations for oil spill contingency management is highly dependent on the relative importance of environmental resources that are potentially subject to oil spill damage. More guidance is needed for decision makers responsible for cleanup planning to understand how the different cleanup options are perceived by the public. We studied the willingness of Chinese households to pay for the cleanup of coastal environmental resources suffering from oil pollution. Choice Experiments (CEs) were one of the stated preference methods from environmental economics proposed for application to oil spill contingency management in the Chinese Bohai Sea. Unlike a conventional stated preference method such as the Contingent Valuation Method ( CVM ), the Choice Experiments (CEs) method distinguishes the value of each coastal resource rather than presenting a total value of all surveyed resources (Baral et al., 2008; Horne et al., 2003; Lehtonen et al., 2003; Rolfe et al., 2000). It is able to distinguish the value of individual attributes of multi-attribute goods. CEs is a structured technique where respondents choose a preferred alternative from a set of multiple alternatives. The random utility theory underlying the CEs technique provides the theoretical basis for integrating choice behavior with economic valuation (Turner et al., 1998). Hanemann (1984) and Hanemann and Kanninen ( 1996 ) described the utility function and its regression model in detail. To complete CEs for estimating public willingness to pay to save coastal resources from oil pollution, a questionnaire was designed. Then it was followed by a survey to collect data for regression. Complete procedures for applying CEs can be seen in Adamowicz et al. (2005), Bullock et al. (1998) and Boxall et al. (1996). The questionnaire needs careful design, otherwise it may influence results from information bias, interviewer bias, hypothetical bias and vehicle payment bias, as described by Mitchell and Carson (1989). We used the questionnaire of Liu et al. (2009) and applied it to the Bohai Sea case. A detailed design of the questionnaire and its choice sets is found in Liu et al. (2009).

\section{INVESTIGATION AREA}

The Bohai Sea is a shallow marginal inland sea located on the northeast coast of China. Its northern, western, and southern boundaries are surrounded by three provinces and two mega cities (i. e., Beijing and Tianjin). Only its eastern part is open to the Yellow Sea, which is connected to the East Sea of China. The Circum-Bohai Sea area is a highly developed economic zone with a variety of Chinese industries. It is also characterized by diverse but vulnerable coastal ecosystems including wetlands, estuaries, beaches, tidal flats, lagoons, islands and marine life (Sun et al., 2015 ). However, rapid economic development has increased pollution in these coastal ecosystems. From 1973 to 2009, the Bohai Sea had 100 oil spills related to shipping ( Lao, 2003). Figure 1 shows the historical record of oil spills in the study area. Besides ship related oil spills, accidents caused by pipeline leaks and blowouts have become more common recently. On July 16, 2010, 1500 tons of heavy oil caused by the explosion of an oil pipeline close to the Dalian harbor spilled into the Bohai Sea and polluted nearly $183 \mathrm{~km}^{2}$ of sea water surface. More than 1000 boats were involved in the cleanup (XINHUA Press, 2010).

\section{QUESTIONNAIRE}

To assess the opinion of Chinese which might have for preventing pollution of coastal from oil pollution, a questionnaire, modified from Liu et al. (2009), was used in a survey. The questionnaire had multiple of questions.

The questions were classified into three major parts: 1) attitudinal and behavior questions; 2 ) evaluation questions, and 3 ) demographic questions. Questions in the first section focused on respondent views and awareness of issues related to oil spills. We attempted to construct a hypothetical market for coastal resources in the second part of the questionnaire. The evaluation questions contained a set of choices, in which benefits of saved/protected coastal resources and costs of the oil spill cleanup response were addressed. In total, we asked 8 evaluation questions. There were 3 options including two costly spill cleanup options and one "do nothing" option with no payment in each evaluation question. Four key attributes were selected as ecological benefits of employing an oil spill cleanup/response. These were beaches, coastal water, sea birds, and collected oil (percent). Beaches refer to the sandy beaches which people use for recreation activities. Beaches, coastal water, and sea birds represent visible coastal resources that are vulnerable to oil spills. The first cleanup responses following an oil spill are always directed at coastal waters, beach restoration, and saving sea birds and marine mammals. A single cost attribute (i. e., one yearly payment for a household to maintain spill cleanup readiness) was presented. During the survey, respondents were asked to select their preferred choice. The final part of the questionnaire (i. e., demographic questions) recorded socio-economic status of the respondent. Questionnaire details and choice sets are similar to those used by Liu et al. (2009).

\section{SURVEY}

A total of 20 trained undergraduate students conducted the survey on the Yantai coast of the Bohai Sea on August 22, 2010 (Figure 1). To facilitate comparison with a previous German survey (2007), tourists visiting recreational resorts along the Yantai coast were randomly selected and interviewed, verbally. The selected tourists were approximately representative of the gender and age distribution of the general population. A total of 247 tourists participated in the survey. Explanatory help was provided by the student interviewers when requested. Each participant answered 8 questions providing a grand total of 1976 observations. Among these, the expensive oil cleanup response option was selected 1431 times.

\section{RESULTS}

The behavioral attitude responses indicated a high awareness of oil spill problems among Chinese households. Among the respondents, $89.5 \%$ had previously seen an oil spill described in media reports. Many interviewees $(37.2 \%)$ were aware of the oil spill caused by the Tasman oil tanker collision on November 23, 


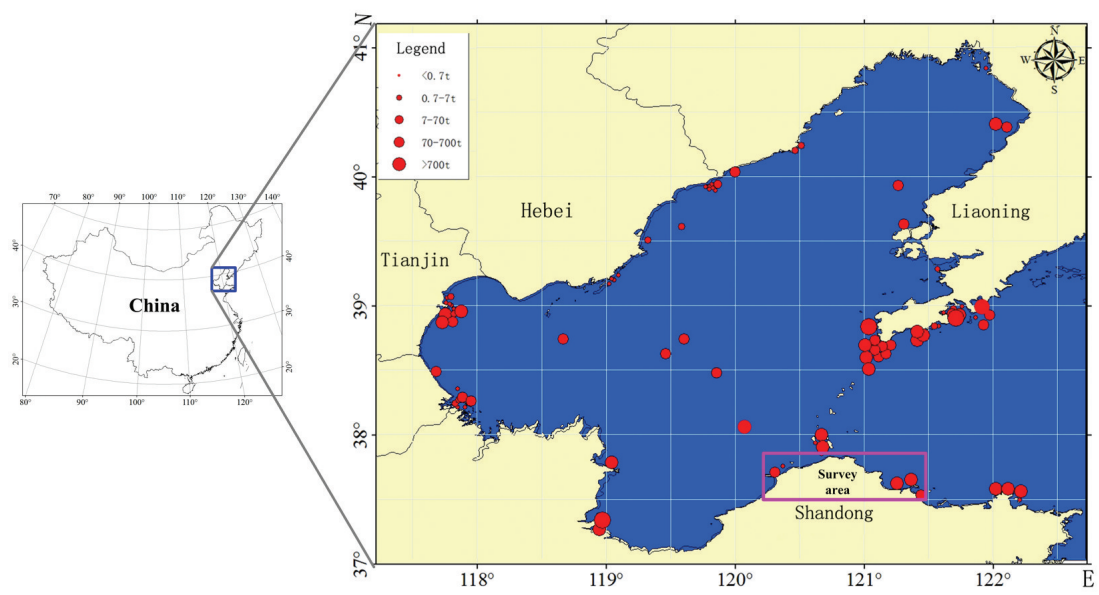

Figure 1. The investigation area and historical oil spills between 1973-2009 (modified from Lao (2003)). The area in blue indicates the Bohai Sea

2002 in the Bohai Sea. In addition to the questions on awareness of oil spills, several attitudinal questions were asked. Statements were coded according to the scale: 1 . Strongly agree; 2 . Agree; 3. Neither agree nor disagree; 4. Disagree. When asked to comment on the following statements: (1) an oil spill is one of the major threats to sea waters; (2) it is a major problem that birds or other species may be killed by oil spills and (3) coastal beaches or other habitats can be severely polluted and damaged by oil spills, the percentages of respondents strongly agreeing were $80.6 \%, 90.7 \%$, and $83.8 \%$ corresponding to those statements, respectively. Regarding the protection priority for coastal environmental resources or public property, $29 \%$ of respondents believed that plants/marshes should receive initial protection from oil pollution. Other environmental features like sea birds, beaches, seals, and tidal flats were considered as high priority for protection by only $25 \%, 22 \%, 14 \%$, and $10 \%$ of interviewees (Figure 2). All respondents were tourists, and they were divided into 5 groups according to their number of visits to Bohai Sea areas. Nearly $36 \%$ of the respondents visited the coastal areas $>3$ times per year and only a small percentage $(2.8 \%)$ of respondents, were first time visitors (Figure 3 ).

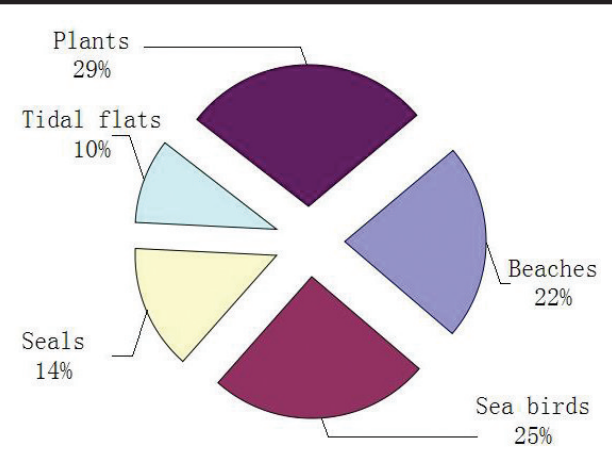

Figure 2. Statistical distribution of protection priorities to different coastal environmental resources or goods

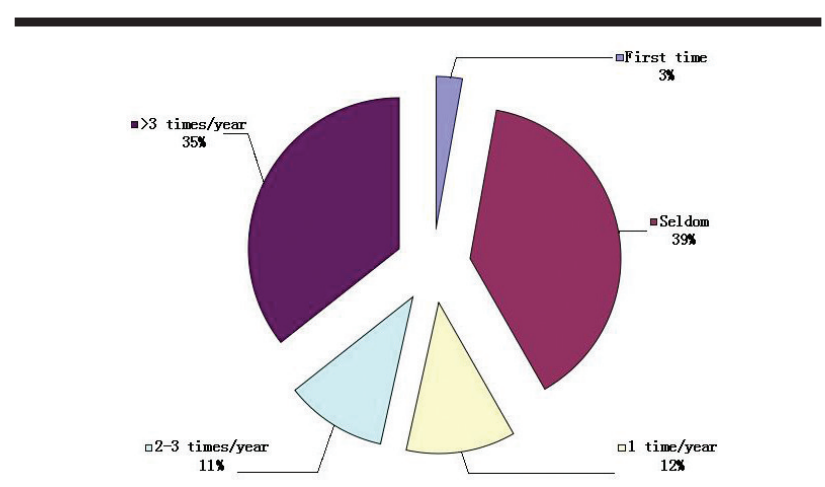

Figure 3. Annual frequency of visits to the Chinese Bohai Sea

Among the behavior questions, respondents were asked to select activities that they participated in during their visits. Entertainment was the most popular activity $(66.3 \%)$ followed by walking, sun bathing, swimming, observing birds and surfing (Figure 4 ). Nearly $75 \%$ of respondents stated that their total number of different activities was 3 or less (Figure 5).

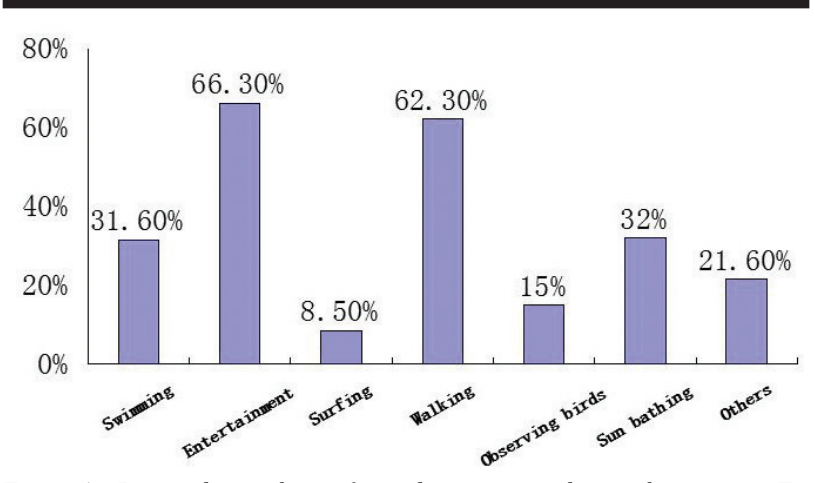

Figure 4. Respondents' share of popular activities during their visits. Entertainment includes playing on the beach and rowing a boat 


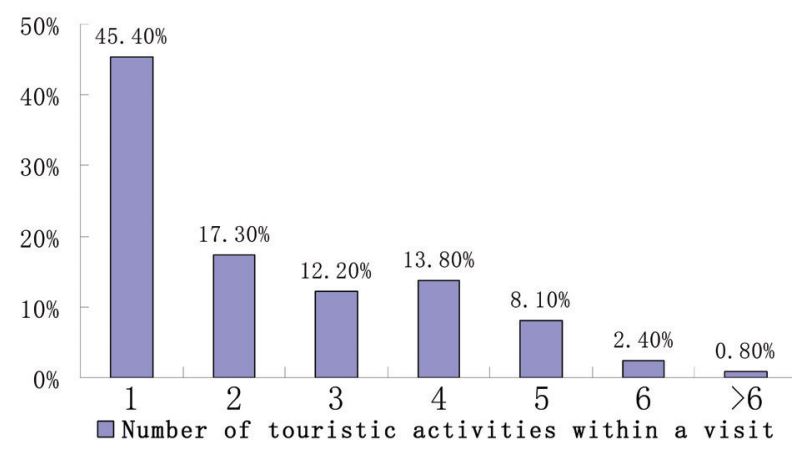

Figure 5. Total number of different types of activities done during all visits by respondents; $45.4 \%$ of respondents stated that they only did one type of activity during all of their visits
In addition to behavior and attitudinal questions, socioeconomic data related to respondents and their households were also recorded. Descriptive statistics are shown in Table 1. In the study sample, males represented $51 \%$ of the total. The mean age and household size of the respondents were 31.37 years and 3.94 persons $(3.94=$ Adult + Children $=3.43+0.51)$. Compared with the national population census data (i. e., the percent males: $51.27 \%$, average age: 32.476 , household size: 4.1 persons ), the sample was reasonably representative. All environmental attributes had been pre-assigned with 2 different values in the questionnaire. For example, coastal water under protection was assumed to be $130 \mathrm{~km}^{2}$ or $200 \mathrm{~km}^{2}$ and oil collected during cleanup was assigned to be either $25 \%$ or $50 \%$ of the total spilled amount. Only the payment attribute was split into 4 levels: $¥ 0$, $¥ 20$, $¥ 50$, ¥ 150 . An orthogonal design process was used to select 8 combinations of the choices among the total array of 64 possible profiles $(2 * 2 * 2 * 2 * 4)$ to be presented in the questionnaire.

Table 1. Descriptive statistics of respondents $(N=247)$ and summary of environmental attributes

\begin{tabular}{|c|c|c|c|}
\hline Social and economic characteristics & Min & $\operatorname{Max}$ & Mean ( S. D. ) \\
\hline Age of respondent & 16 & 78 & $31.37(13.307)$ \\
\hline The total number of adults in household & 1 & 12 & $3.43(1.199)$ \\
\hline \multirow[t]{2}{*}{ The total number of dependent children in household } & 0 & 3 & $0.51(0.616)$ \\
\hline & \multicolumn{3}{|c|}{ Percent $(\%)$} \\
\hline
\end{tabular}

Gender $($ male $=1$, female $=0)$

Education attainment (Education attainment ( primary school $=1$, middle school $=2$, high middle school $=3$, university or college $=4$, graduates and above $=5$, others $=0$ )

Resident location ( living in provinces and cities surrounding the Bohai sea $=1,0$ otherwise)
$51 / 49$

\section{$4.5 / 10.1 / 30.4 / 49 / 5.7 / 0.4$}

$87.9 / 12.1$

$22.3 / 42.5 / 15.4 / 6.9 / 7.3 / 3.2 / 1.2 / 1.2$

Membership of environmental organization $($ yes $=1$, no $=0$ )

$6.1 / 93.9$

Have you observed birds during your visits? ( yes $=1$, no $=0$ )

Have you ever seen an oil spill from TV or newspaper? ( yes $=1$, no $=0$ )

Is oil spill one of major threats to sea water? ( Strongly agree $=1$; Agree $=2$; No idea $=3$; Disagree $=4$ )

80. 6/14.6/3.6/1.2

\begin{tabular}{|c|c|c|c|}
\hline Environmental attributes & Min & $\operatorname{Max}$ & Mean (S. D. ) \\
\hline Water $\left(\mathrm{km}^{2}\right)$ & 130 & 200 & $174.18(33.78)$ \\
\hline Beach ( km) & 30 & 80 & $60.74(24.337)$ \\
\hline Sea bird & 5000 & 15000 & $13770.24(3284.925)$ \\
\hline Oil collection ( $\%$ ) & 25 & 50 & $40.78(12.066)$ \\
\hline Payment ( $¥$ ) & 0 & 150 & $74.98(61.3)$ \\
\hline
\end{tabular}


A conditional Logistic model calculation was performed using SPSS statistical software. In the regression model, the dependent variable was the individual response to option A (i. e., the first option) in each choice set and the independent variables were the collection of attributes including environmental and demographic factors. All listed attributes were statistically significant in the model at conventional levels, as significance levels ranging from $1 \%$ to $10 \%$ are exhibited, as shown in Table 2 . So the utility of the household can be expressed as follows:

Utility $=0.007 * W A T+0.007 * B E A+7.44 E-$

$5 * B I R-0.34 * M E E-0.01 * P A Y-0.193 * C H D+$

$0.146 * E D U+0.123 * A D U+0.147 * I N C+0.027 * A G E-$

$$
0.981 * O F T+0.356 * S W I+0.004 * H E R * P A Y-
$$$$
0.104 * H E R * I N C
$$

The regression was used to estimate marginal rates for the continuous variables: coastal water, beaches, and sea birds (Table 3 ). For example, the mean marginal rate for beach reflects that each unit increase $(1 \mathrm{~km})$ in the length of beaches protected from oil spills had a marginal value of $¥ 0.7$ per household. In this survey, beach length in $\mathrm{km}$ and water in $\mathrm{km}^{2}$ were valued equally by respondents. These level of these values was followed by that of sea birds. A $1 \mathrm{~km}$ beach could be equated to 94 sea birds in monetary terms in this hypothetical market survey.

Table 2. Conditional logistic model with interactions for oil spill combat service attributes

\begin{tabular}{|c|c|c|c|}
\hline \multicolumn{2}{|r|}{ Variable } & \multirow{2}{*}{ Coefficient } & \multirow{2}{*}{ S. E. } \\
\hline Symbol & Definition & & \\
\hline WAT & Saved Coastal waters $\left(\mathrm{km}^{2}\right)$ during the cleanup. Numerical variable & $0.007^{* * * *}$ & 0.001 \\
\hline BEA & Saved beaches in $\mathrm{km}$ during the cleanup. Numerical variable & $0.007^{* * * *}$ & 0.002 \\
\hline BIR & Saved sea birds during the cleanup. Numerical variable & $7.44 \mathrm{E}-5^{\text {***** }}$ & $1.61 \mathrm{E}-5$ \\
\hline MEE & $\begin{array}{l}\text { Is an oil spill one of major threats to sea water? Ordinal variable: Strongly agree }=1 ; \text { Agree }=2 ; \text { No idea }=3 \text {; } \\
\text { Disagree }=4\end{array}$ & $-0.34^{\text {****** }}$ & 0.088 \\
\hline PAY & Yearly payments made by each household for using strategy to respond to the spill. Numerical variable & $-0.01^{\text {**** }}$ & 0.001 \\
\hline CHD & Continuous variable indicating the total number of children in the household & $-0.193^{* * *}$ & 0.086 \\
\hline EDU & $\begin{array}{l}\text { Education attainment }(\text { primary school }=1, \text { middle } \text { school }=2 \text {, high middle school }=3 \text {, university or college }=4 \text {, } \\
\text { graduates and above }=5\end{array}$ & $0.146^{* * * *}$ & 0.057 \\
\hline $\mathrm{ADU}$ & Continuous variable indicating the total number of adults in the household & $0.123^{* * * *}$ & 0.044 \\
\hline INC & $\begin{array}{l}\text { Ordinal variable represents monthly net income of household. less than } ¥ 2000=1 \text {, between } ¥ 2001 \text { and } \\
¥ 4000=2 \text {, between } ¥ 4001 \text { and } ¥ 6000=3 \text {, between } ¥ 6001 \text { and } ¥ 8000=4 \text {, between } ¥ 8001 \text { and } \\
¥ 10000=5 \text {, between } ¥ 10001 \text { and } ¥ 15000=6 \text {, between } ¥ 15001 \text { and } ¥ 20000=7 \text {, more than } ¥ 20000 \\
=8\end{array}$ & $0.147^{* * * *}$ & 0.047 \\
\hline AGE & Continuous variable indicating theage of the respondent & $0.027^{* * * * *}$ & 0.004 \\
\hline OFT & Do you often go to the coast? Yes $=1, \mathrm{No}_{0}=0$ & $-0.981^{* * * *}$ & 0.212 \\
\hline SWI & Do you often swim when you go to the coast? Yes $=1$, No $=0$ & $0.356^{* * * *}$ & 0.122 \\
\hline $\mathrm{HER} * \mathrm{PAY}$ & Have you heard the Tasman oil spill in China 2004 from TV or newspaper? Yes $=1$, No $=0$ & $0.004^{* * * *}$ & 0.002 \\
\hline $\mathrm{HER} * \mathrm{INC}$ & Have you heard the Tasman oil spill in China 2004 from TV or newspaper? Yes $=1, N_{0}=0$ & $-0.104^{*}$ & 0.054 \\
\hline \multicolumn{4}{|c|}{$\chi^{2}(12)=634.336($ significant at 0.000 level $)$} \\
\hline Sample si & $=1976(247 * 8)$ & & \\
\hline
\end{tabular}

Table 3. Partial-worth of environmentally related attributes

\begin{tabular}{cc}
\hline \hline Attributes & Part-worth \\
\hline Water & $-\beta_{\text {water }} / \beta_{\text {payment }}=¥ 0.7 / \mathrm{km}^{2}$ \\
Beach & $-\beta_{\text {beaches }} / \beta_{\text {payment }}=¥ 0.7 / \mathrm{km}$ \\
Bird & $-\beta_{\text {duck }} / \beta_{\text {payment }}=¥ 7.44 \mathrm{E}-3 / \mathrm{bird}$ \\
\hline
\end{tabular}




\section{DISCUSSIONS}

A sample of 247 tourists, roughly representative of the national Chinese population, were interviewed. Each interviewee responded to 8 questions generating a total of 1976 observations which was sufficient for statistical analysis of an econometric model.

Among the observations, a costly oil spill cleanup/response option was chosen 1431 times. This high proportion reflected either a strong interest in environmental issues among the respondents or approval for yearly payments to be used for an alternative cleanup/response option or both.

The model indicated that families with more and younger adults, fewer children, and higher monthly household income, and a higher educational background were more likely to express willingness to pay for the costly oil spill cleanup option that would protect more environmental resources from pollution. As total of $77 \%$ of respondents with a university or advanced education were willing to pay for the cleanup option, while this choice was made by only $43.8 \%$ of respondents with primary school education or less (Figure 6). Also the percentage of households saying "yes" to the alternative option increased as monthly income increased. In terms of the parameter of children, households with fewer children were more favorable toward paying for the costly cleanup option. Households with fewer children may have a larger surplus of money that could be used to support the costly alternative cleanup option. Respondent age was a parameter that was negatively correlated to household's willingness to pay for preventing coastal resources from oil pollution in this case study.

Table 3 shows that both coastal water $\left(\mathrm{km}^{2}\right)$ and beaches $(\mathrm{km})$ were judged to be more valuable than sea birds in the view of Chinese households. This can be understood by examining human activities during their seaside visits. Most people had entertainment activities including walking, sun bathing, swimming and general use of the beaches and water. Only a small percent of people ob- served birds during their visits.

In order to reduce the frustration of survey respondents, we only presented three coastal ecosystems (i. e., water, beaches, and birds ) in the questionnaire and we kept the number of questions as small as possible. Other important ecosystems like wetlands and tidal flats could be included with pre-assigned values in the questions to extend the survey, if desired.

\section{CONCLUSIONS}

A hypothetical market was constructed by using Choice Experiments (CEs) for transaction of non-economic coastal resources including coastal water, beaches, and sea birds. We applied the questionnaire of Liu et al. (2009) to a case study of oil spill contingency management in the Chinese Bohai Sea. Our findings support ongoing discussions about the level of preparedness of coastal spill cleanup facilities and help to analyze public management preferences. Environmental and monetary attributes and household characteristics influence support for costly cleanup options. Chinese household concern for coastal resources (i. e., coastal water, beaches, and birds) is significant and so this group expresses willingness to pay for costly cleanup activity to save additional resources from oil spill pollution. The significant impact of a yearly payment on household budgets indicates that an environmentally friendly cleanup option must be a relatively minor household cost. Finally, households with fewer children and more young adults, higher monthly income, higher education level, were likely to prefer a more costly, but environmentally friendly scenario. Such a demographic trend does not imply that these findings can be transferred to other cases across countries without additional study. This work contributes to initial contingent valuation studies in China and provides an opportunity to compare expressed values of coastal ecosystems with previous studies done in North America and Europe. The results enable a comparison of the similarity of coastal valuation results across countries.

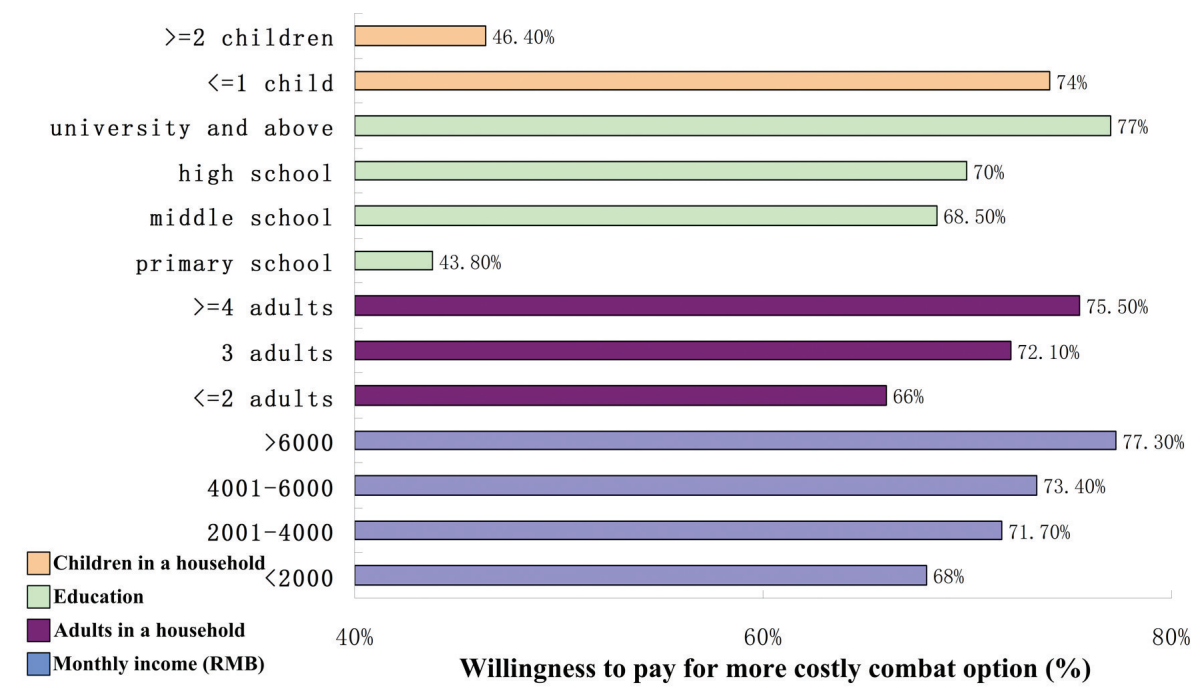

Figure 6. Positive and negative effects of the demographic characteristics of households on the choice of a costly oil spill response strategy 


\section{ACKNOWLEDGMENTS}

This study was made possible thanks to the jointly financial support from the Key Deployment Project of the Chinese Academy of Sciences (Grant NO. KZZD-EW-14), the National Program on Key Basic Research Project of China ( 973 Program, 2015CB453300) and the National Science Foundation, China with a reference of 41371483 .

\section{LITERATURE CITED}

Adamowicz, V.; Hanley, N., and Wright, R. E., 2005. Price vector effects in choice experiments. Resource and Energy $E$ conomics, 27, 227-234.

Alló, M.; Maria, L., and Loureiro, M. L., 2013. Estimating a meta-damage regression model for large accidental oil spills. Ecological Economics, 86, 167-175.

Baral, N.; Stern, M. J., and Bhattarai, R., 2008. Contingent valuation of ecotourism in Annapurna conservation area, Nepal: Implications for sustainable park finance and local development. Ecological Economics, 66, 218-227.

Birkland, T. A. and Lawrence, R. G., 2002. The social and political meaning of the Exxon Valdez oil spill. Spill Science \& Technology Bulletin, 7, 17-22.

Boxall, P. C.; Adamowicz, W. L.; Swait, J.; Williams, M., and Louviere, J., 1996. A comparison of stated preference methods for environmental valuation. Ecological Economics $18,243-253$.

Bullock C. H.; Elston D. A., and Chalmers N. A., 1998. An application of economic choice experiments to a traditional land use-deer hunting and landscape change in the Scottish Highlands. Journal of Environmental Management, 52, 335-351.

Costanza, R.; d'Arge, R.; Groot, de R.; Farberk, S.; Grasso, M.; Hannon, B.; Limburg, K.; Naeem, S.; O’Neill, V. R.; Paruelo, J.; Raskin, R. G.; Suttonkk, P., and den Belt, van M., 1997. The value of the world's ecosystem services and natural capital. Nature, 387, 253-260.

COPC, 2012. http: // www. conocophillips. com. cn/EN/ Response/Pages/default. aspx

Hanemann, W. M., 1984. Welfare Evaluation in Contingent Valuation Experiments with Discrete Responses. American Journal of Agricultural Economics, 66, 332-341.

Hanemann, W. M. and Kanninen, B., 1996. The Statistical Analysis of Discrete-Response CV Data. Working Paper No. 798. Department of Agricultural and Resource Economics, University of California at Berkeley.

Horne, P.; Boxall, P. C., and Adamowicz, W. L., 2003. Multiple-use management of forest recreation sites: a spatially explicit choice experiment. Ecology and Management, 207, 189-199.
Lehtonen, E.; Kuuluvainen, J.; Pouta, E.; Rekola, M., and Li, C., 2003. Non-market benefits of forest conservation in southern Finland. Environmental Science \& Policy, 6, 195 -204 .

Liu, D. and Zhu, L., 2014. Assessing China's legislation on compensation for marine ecological damage: A case study of the Bohai oil spill. Marine Policy, (50), 18-26.

Liu, X.; Wirtz, K. W.; Kannen, A., and Kraft, D., 2009. Willingness to pay among households to prevent coastal resources from polluting by oil spills: A pilot survey. Marine Pollution Bulletin, 58, 1514-1521.

Lao, H., 2003. Statistical records of oil spills larger than 50 tons in the Chinese Sea for the last 29 years. Environmental protection in transportation, 24, 46-46.

Mitchell, R. C. and Carson, R. T., 1989. Using surveys to value public goods: the contingent valuation method. Washington, DC: Resource for the Future.

Ofiara, D. D., 2002. Natural resource damage assessments in the United States: rules and procedures for compensation from spills of hazardous substances and oil in waterways under US jurisdiction. Marine Pollution Bulletin, 44, 96-110.

Ojeda, M. I.; Mayer, A. S., and Solomon, B. D., 2008. Economic valuation of environmental services sustained by water flows in the Yaqui River Delta. Ecological Economics, 65, $155-166$.

Rolfe, J.; Bennett, J., and Louviere, J., 2000. Choice modelling and its potential application to tropical rainforest preservation. Ecological Economics, 35, 289-302.

Spurgeon, J., 1999. The Socio-Economic Costs and Benefits of Coastal Habitat. Rehabilitation and Creation. Marine Pollution Bulletin, 37, 373-382.

Stål, J.; Paulsen, S.; Pihl, L; Rönnbäck, P.; Söderqvist, T., and Wennhage, H., 2008. Coastal habitat support to fish and fisheries in Sweden: Integrating ecosystem functions into fisheries management. Ocean \& Coastal Management, 51, 594 -600 .

Sun, Z.; Sun, W.; Tong, C.; Zeng, C.; Yu, X., and Mou, X., 2015. China's coastal wetlands: Conservation history, implementation efforts, existing issues and strategies for future improvement. Environment International, 7, 25-41

Turner, R. K.; Adger, W. N., and Lorenzoni, I., 1998. Towards Integrated Modelling and Analysis in Coastal Zones: Principles and Practice. LOICZ Reports and Studies No. 11. Centre for Social and Economic Research on the global environment, University of East Anglia and University College London.

XINHUA Press, 2010. http: // green. sina. com. cn/news/roll/ 2010-07-20/105320717428. shtml. 